\title{
An Ultra-Brief Mindfulness-Based Intervention for Patients in Treatment for Opioid Addiction with Buprenorphine: A Primary Care Feasibility Pilot Study
}

\author{
Jessica Bloom-Foster, MD, and Lewis Mehl-Madrona, MD, $\mathrm{PhD}^{1-5}$
}

\begin{abstract}
Objectives: To demonstrate the feasibility and acceptability of a brief mindfulness-based intervention taught by physicians for patients with opioid addiction and to determine if the intervention reduces likelihood of relapse or treatment failure within 6 months.

Design: A prospective, feasibility, single-group, cohort pilot study.

Setting: A Family Medicine teaching clinic serving a mixed urban and rural population in Bangor, Maine.

Subjects: Adult patients initiating outpatient treatment for opioid addiction with buprenorphine $(N=40)$.

Interventions: Study physicians conducted a 10- to 12-min education session for all patients starting treatment during the enrollment period, including a 5-min mindfulness exercise. Enrolled subjects received an MP3 player loaded with six mindfulness audio exercises $(5-19 \mathrm{~min})$ and were instructed to practice at least $5 \mathrm{~min}$ daily and record their practice in a logbook.

Outcome measures: Acceptability and subjective usefulness to recovery were evaluated at 2, 4, and 6 months of follow-up, with qualitative analysis of themes in recorded poststudy interviews. Logbook entries and tabletbased surveys provided data on home mindfulness practice, classified as "high" or "low." Relapse or treatment failure was documented.

Results: Feasibility and acceptability were demonstrated with $82 \%$ enrollment and $100 \%$, 97\%, and $90 \%$ completion of follow-up visits at 2, 4, and 6 months, respectively, among those still in treatment. Sustained positive impressions of the intervention and exercises remained at 6 months. Relapse or treatment failure was reduced in the "high" practice uptake group compared with "low" practice uptake (11\% vs. 42\%, $p=0.033)$.

Conclusions: In contrast to more intensive 8-week models of meditation training, this study demonstrates that even a brief single training session can induce sustained home meditation practice that subjectively helped patients in recovery for opioid addiction and was associated with lower risk of relapse. Brief mindfulness-based interventions may be useful to increase access to mindfulness training in this population.
\end{abstract}

Keywords: mindfulness, addictions, family medicine, meditation, qualitative research, opiate use disorder

Introduction

$\mathbf{O}$ PIOID USE DISORDER (OUD) is a chronic relapsing condition where craving and negative affect are strong predictors of relapse. ${ }^{1,2}$ Mindfulness-based relapse preven- tion $^{3-12}$ is modeled on the 8-week mindfulness-based stress reduction (MBSR) course pioneered by Kabat-Zinn in the early $1980 \mathrm{~s},{ }^{13}$ which has shown benefit in a variety of chronic medical and psychological conditions: anxiety, chronic pain, tobacco cessation, and others. ${ }^{8,14-21}$ Adapting this method for

\footnotetext{
${ }^{1}$ Family Medicine Residency, Northern Light Eastern Maine Medical Center, Bangor, ME.

${ }^{2}$ Coyote Institute, Orono, ME.

${ }^{3}$ Wabanaki Health and Wellness, Bangor, ME.

${ }^{4}$ Graduate School, University of Maine, Orono, ME.

${ }^{5}$ Department of Psychiatry, University of Vermont College of Medicine, Burlington, VT.
} 
relapse prevention shows promise for reducing actual substance use, cravings, and rate of relapse over 12 months when used as an early after-care program for patients following intensive addiction recovery programs, although effect sizes are estimated to be small ( $g=0.08-0.20$ in these studies). ${ }^{3,5}$ Potential neurobiological mechanisms through which the practice of mindfulness meditation may augment addiction treatment success involve the attenuation of craving via both "top-down" (greater executive control over the behavioral response to craving) and "bottom-up" (modulating the negative subjective experience of craving) pathways., 6,20,22

Recent data showing that low dispositional mindfulness correlates with self-medication of negative emotion with opioids further suggest that mindfulness training may attenuate self-medication. ${ }^{23}$ Unfortunately, standard MBSRbased mindfulness training requires extensive time commitment and cost and is not available in most rural primary care settings.

Improving the long-term success of addiction treatment will require greater availability of effective relapse prevention programs and strategies. Although patients with opiate addiction are often identified in the primary care office setting, and a growing number of primary care physicians offer office-based buprenorphine treatment programs, very little research has been performed in this setting to evaluate relapse prevention techniques, or specifically to assess the feasibility and effectiveness of mindfulness-based relapse prevention techniques or programs in primary care. A systematic review of mindfulness meditation for substance use disorders suggests that because mindfulness skills reduce anxiety, depression, and perceived stress, all known risk factors for relapse, they may be particularly helpful for patients with co-occurring mental health diagnoses.?

The authors hypothesized that patients starting treatment in the outpatient setting for opioid addiction would be willing to participate in research on a brief primary care intervention to teach relapse prevention through mindfulness meditation skills, that the brief intervention would induce significant uptake of home mindfulness practice, and would decrease relapse-related behaviors, cravings, and negative affect over 6 months of follow-up.

\section{Materials and Methods}

\section{Study design}

This was a prospective, feasibility, single-group, cohort pilot study allowing evaluation of the intervention's feasibility and acceptability to this population. The Northern Light Eastern Maine Medical Center Institutional Review Board approved the study protocol before any subject enrollment. The intervention (a 10- to 12-min, scripted, timed educational session containing an embedded 5-min practice exercise, accompanied by a paper handout) was delivered by one of three family medicine physicians, all of whom who had training in mindfulness meditation, either at an introductory group session or in a one-on-one session at a regularly scheduled clinic appointment. The three physicians had practiced before a fourth independent physician until all were satisfied that the delivery of each physician was the same. Subjects received an MP3 player preloaded with six different mindfulness audio exercises recorded by the study team for home practice (ranging from 5 to $19 \mathrm{~min}$ long), largely based on existing materials (with permissions), as well as a small paper logbook to record practice. Baseline and follow-up data were collected by electronic survey on a tablet at enrollment and at $\sim 2,4$, and 6 months from study intervention date, capturing patients when they were seen for routine scheduled follow-up appointments in the clinic.

Patients were compensated with "gas cards" (\$10 gift cards for an area gas station) for their participation. They received $\$ 20$ in gas cards for the enrollment process and $\$ 10$ at each of the follow-up appointments if they completed the surveys and turned in a logbook for copying. If they did not have the logbook with them, the gas card was left in a sealed envelope at the front desk where they could pick it up when they brought the logbook. An additional \$20 was provided in gas cards for participating in a poststudy interview.

Subjects were approached and asked to participate in a poststudy exit interview when they came for appointments at the clinic; those who could stay after their appointment or return at a later time for an interview became the sample.

All patients presenting for intake to the medication-assisted treatment (MAT) program were offered enrollment. Efforts were made to enroll patients as close to their induction into MAT as possible and to conduct the intervention as close to enrollment as possible. The goal of this study was to capture subjects early in treatment when symptoms of addiction, withdrawal, and cravings could still be significant at baseline. The enrollment survey included questions about subjects' access to technology and transportation.

\section{Data collection}

Baseline historical and demographic data, and subsequent outcomes-related data, were abstracted from the electronic medical record (EMR) into Excel files.

Baseline tablet surveys included questions about technology and contact preferences and access, and follow-up surveys at 2, 4, and 6 months also included Likert scale questions about the usefulness of the mindfulness practice. Subjects were generally left to complete the tablet-based surveys alone in the examination room following set up by study personnel, and the anonymity of their responses was emphasized at each visit.

Subjects were asked to bring their logbooks with recorded practice data to every office visit, and completed pages were photocopied and placed in a file for data entry. Logbook data identified subjects who were high utilizers of the mindfulness behavioral intervention and those with high persistence and allowed qualitative analysis of the comments subjects wrote in their books. Following 6 months of subject enrollment, questions were added to the follow-up surveys at 2, 4 and 6 months regarding days since last mindfulness practice, frequency of practice in sessions per week, and average length of a practice session, based on subject recall. The authors were therefore able to acquire these additional data as a backup to the logbooks and to replace the logbook data for those subjects who would not keep a $\log$ or remember to bring it to their appointments.

\section{Variables}

Covariates. Covariates collected from the EMR included age, gender, pregnancy status, partner presence and substance abuse status, children, drug of choice and route of 
ingestion, coexisting mental health and chronic pain diagnoses, previous exposure to addiction treatment, ACE score (adverse childhood events, 0-10), and buprenorphine dosing (initial and final at 6 months).

Dependent variables. Primary outcome was a designation as "treatment failure" based on a documented relapse event or leaving treatment due to noncompliance with the program. Frequency, intensity, and persistence of home mindfulness practice were collected using logbooks, surveys, and interviews.

\section{Analysis}

To differentiate higher levels of practice versus lower levels, the authors each independently reviewed de-identified data about levels of practice based on copied paper logbook data, additional survey questions added to the follow-up visits, and exit interview data, triangulating sources whenever possible. The authors then reviewed all the records together and discussed criteria for what would constitute higher levels of practice and what would constitute lower levels. Then, the authors independently rated the de-identified subjects for level of practice. The aim was to achieve at least $80 \%$ interobserver reliability.

The authors began by discussing the boundary between groups using data only about practice frequency (identifying information and outcomes removed), first using three groups of level of practice, and then, using two. The authors then independently rated levels of practice without knowledge of patient outcome and assessed the interobserver reliability. Chi-square methods were used to compare the proportion of subjects relapsing in the higher practice group with the proportion relapsing in the lower practice group. Multivariate methods with general linear modeling were used to explore the relation of covariates to outcome.

\section{Qualitative data analysis}

The authors used the constant comparative method, as well as theoretical memo writing (starting with whatever ideas the text inspired), then theoretical coding to come to a higher level of understanding of what common areas might exist in the stories people told, and then, theoretical sorting in which these memos were organized into similar themes, following the procedures that have been used elsewhere. ${ }^{24}$ The authors repeated this process iteratively until the themes were arrived on which we could agree existed. Idiosyncratic categories that only appeared once were ignored since they referred to individual experiences not shared by other participants and therefore, while interesting, not relevant to the aim of finding the common elements that people reported about participating in this study. The authors were most interested in presenting what participants would say was the value of mindfulness practice for them and how it affected their process of recovery.

The authors read each transcript with an eye to the question of "What is being said here?" The authors used a variety of colors to highlight text that interested us as saying something about the person, about his or her experience with mindfulness practice, and about other stressors or conditions that affected mindfulness practice and their journey toward recovery. The colors denoted the earliest separation of the data into broad categories. When the authors had gone through the transcripts several times to find everything of potential value, the authors reviewed the highlighted comments, asking the question, what area of concern is this person addressing?

The authors used the constant comparison method to assure that all data were systematically compared with all other data in the data set. ${ }^{25}$ This assures that all data produced will be analyzed rather than potentially disregarded on thematic grounds. The authors wrote memos in the margins of the text to signify the areas that the participants were addressing and what their comments implied. The authors used the constant comparator analysis method to continue to iteratively go through all the transcripts to arrive at a set of organizing themes to describe the experiences and perceptions of participants and what emerged to us about their experiences and perspectives. The authors aimed to allow these themes to emerge through the dialogue among the two of us with the transcript.

In each iteration, the authors commented further upon memos and added questions and notes. During each iteration, the authors asked what similarities existed across participant responses. The authors continued in an iterative process in which transcripts were repeatedly reviewed until consensus was obtained about what was common to the responses of participants.

\section{Results}

\section{Baseline characteristics}

Table 1 shows a summary of baseline characteristics of the study population, with comparison of those classified as "treatment failure" $(n=10)$ and those still in treatment at 6 months $(n=27)$, with no significant differences. Enrolled subjects were $(n=40)$ adult patients (mean age $\pm \mathrm{SD}=32.2$ \pm 7.2 years) inducted in our office onto buprenorphine therapy. Informed consent was obtained from all participants. Twenty-five were female $(62.5 \%)$, and of these, 16 (64\%) were pregnant at the time of enrollment. Two were Native American and the remainder were white.

Baseline data extraction also included documentation of active (within the past 3 months) abuse of other substances and active co-occurring mental health diagnoses. Eightythree percent of participants used tobacco, $78 \%$ used marijuana, 28\% used cocaine, 20\% used alcohol, 35\% used benzodiazepines, and $18 \%$ used stimulants. Half of the subjects enrolled used three or more other drugs in addition to opiates.

Co-occurring diagnoses of depression (50\%) and anxiety $(48 \%)$ were very common, with post-traumatic stress disorder $(30 \%)$, bipolar disorder $(15 \%)$, and attention deficit hyperactivity disorder (18\%) being less common. In summary, this is a young high-risk population with longstanding opioid abuse and significant polysubstance abuse and mental health disorders complicating their treatment.

For analysis, subjects were divided into those still in treatment $(N=27)$ and those who have an event called "relapse" (documented significant opioid substance abuse or otherwise failing or leaving treatment, $N=10$ ) by 6 months following MAT induction date. Three of the 40 enrolled subjects who left the treatment program and the study for reasons other than documented or presumed relapse were 
Table 1. Baseline Information on Demographics, Substance Abuse, Pain Diagnosis, ANd Adverse ChILdHOOd Event ScORES

\begin{tabular}{lccc}
\hline & $\begin{array}{c}\text { Total population } \\
(\mathrm{n}=40)\end{array}$ & $\begin{array}{c}\text { No treatment } \\
\text { failure }(\mathrm{n}=27)\end{array}$ & $\begin{array}{c}\text { Treatment } \\
\text { failure }(\mathrm{n}=10)\end{array}$ \\
\hline Age, years (mean \pm SD) & $32.2 \pm 7.1$ & $31.9 \pm 6.4$ & $33.1 \pm 8.9$ \\
Gender (\% female) & 62.5 & 55.6 & 80.0 \\
\%Pregnant if female & 64.0 & 60 & 75 \\
Age started opioids (mean \pm SD) & $19.0 \pm 6.2$ & 18.2 & 19.4 \\
Length of use, years (mean \pm SD) & $13.2 \pm 7.5$ & $13.7 \pm 6.7$ & $13.7 \pm 9.9$ \\
Drug of choice, $n(\%)$ & $23(57.5)$ & $15(55.6)$ & $7(70)$ \\
Oxycodone & $12(30)$ & $9(33.3)$ & $1(10)$ \\
Heroin & $2(5)$ & $1(3.7)$ & $1(10)$ \\
Buprenorphine & $3(7.5)$ & $2(7.4)$ & $1(10)$ \\
Other & & & \\
Route of choice, $n(\%)$ & $18(45)$ & $6(22.2)$ & $2(20)$ \\
Snort (any) & $8(20)$ & $13(48.1)$ & $5(50)$ \\
IV (any) & $6(15)$ & $1(3.7)$ & $4(40)$ \\
Smoke (any) & $6(15)$ & $4(14.8)$ & $1(10)$ \\
Oral (only) & $2(5)$ & $4(14.8)$ & $0(0)$ \\
Sublingual (only) & $4(10)$ & $1(3.7)$ & $1(10)$ \\
Not specified & $20(50)$ & $14(48.3)$ & $4(40)$ \\
Previous MAT, yes, $n$ (\%) & $9(45)$ & $8(57)$ & $1(25)$ \\
If previous MAT, methadone & $9(22.5)$ & $6(22)$ & $3(30)$ \\
Number with chronic pain dx (\%) & $4.3 \pm 2.9$ & $4.2 \pm 2.8$ & $4.9 \pm 3.2$ \\
ACE score $(n=37,3$ missing) (mean \pm SD) & & & \\
\hline
\end{tabular}

MAT, medication-assisted treatment.

excluded from these analyses. Using two rating groups (high vs. low practice), the interobserver agreement was $97 \%$. A typical high-uptake subject practiced at least three or more times per week for an average of 9-14 min per session. A typical low-uptake subject practiced two or fewer times per week for less than $5 \mathrm{~min}$ per session and sometimes no practice for 7 or more consecutive days.

\section{Feasibility}

Feasibility and acceptability were well demonstrated with an $82 \%$ enrollment rate (40 of 49 approached) and $100 \%$, $97 \%$, and $90 \%$ completion of follow-up visits (among those still in treatment program) at 2, 4, and 6 months, respectively (Fig. 1). Of the nine patients approached who declined

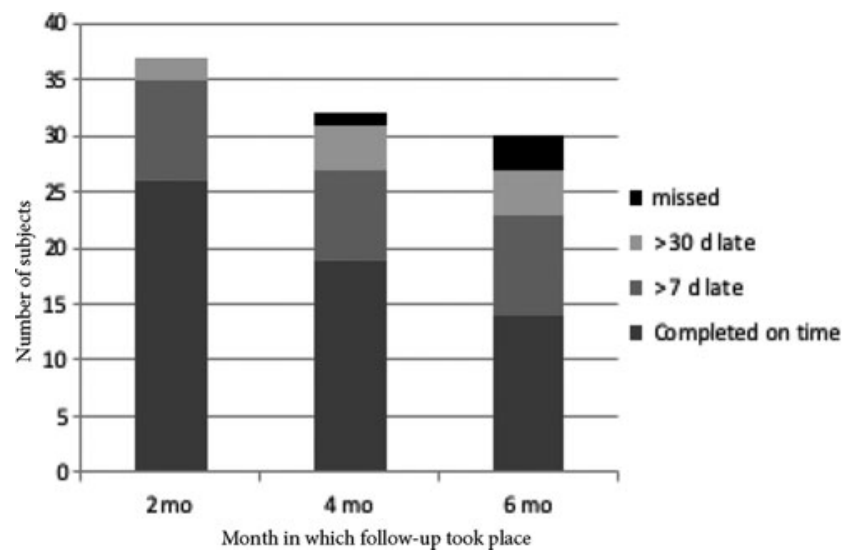

FIG. 1. Completion of follow-up study appointments at 2, 4 , and 6 months. enrollment, four patients stated that they did not have time to complete the enrollment process, three cited unwillingness to make the time commitment to the study or to group visits, and two cited lack of interest.

Five subjects were enrolled before induction (1-8 days), and 30 were enrolled within 14 days following induction. The remaining five were enrolled from 21 to 37 days after induction. Sixteen subjects $(40 \%)$ received the intervention on the same day as enrollment, $15(37.5 \%)$ within 1-7 days, and the remaining $9(22.5 \%)$ ranged from 13 to 25 days after enrollment.

While the intervention was intended to be performed at an introductory group session, due to logistical and scheduling challenges, this group sometimes only contained one patient or did not occur. Ultimately, 16 subjects received the intervention in a one-on-one session and 24 as part of a group of 2-4 patients. The intervention was scripted and was delivered in the same manner, whether to a group of patients or to an individual, always at the end of the visit, and not by the practitioners involved in the visit.

One subject dropped out of the treatment program and the study by entering a residential program within days of enrollment and was removed from any further analysis other than baseline study population description. Two subjects left the treatment program for reasons unrelated to relapse after $\sim 2$ months and were also excluded from comparative analyses.

Owning a smartphone was common $(72.5 \%)$, although three subjects relied on a friend's phone number for the study. Half of subjects had earphones or earbuds (50\%) and computer access (47.5\%). Only $22.5 \%$ owned a CD player and $12.5 \%$ an MP3 player, confirming that providing MP3 players and earbuds for audio exercise access was essential to the success of the study. Only about half the subjects had their own car for transportation $(52.5 \%)$ and a third relied on someone else $(32.5 \%)$. A 
Table 2. Survey Questions at 2 Months of Follow-UP ABOUt THE MindFulness Education Session $(N=34)$

\begin{tabular}{lc}
\hline Question & $\begin{array}{c}\text { Mean Likert } \\
\text { Score } \pm S D\end{array}$ \\
\hline $\begin{array}{l}\text { The doctor who presented the information on } \\
\text { the mindfulness exercise was }\end{array}$ & $5.6 \pm 1.2$ \\
knowledgeable. & \\
$\begin{array}{l}\text { I found the session conducted by the doctor } \\
\text { to be helpful in my early recovery. }\end{array}$ & $4.9 \pm 1.2$ \\
$\begin{array}{l}\text { I would have appreciated my family doctor } \\
\text { teaching me about mindfulness earlier. }\end{array}$ & $3.9 \pm 1.4$ \\
$\begin{array}{l}\text { Mindfulness skills are appropriate for } \\
\text { primary care doctors to teach their } \\
\text { patients. }\end{array}$ & $4.9 \pm 1.1$ \\
\hline
\end{tabular}

small percentage used the bus $(7.5 \%$ ), the Lynx ride system (for medical appointments for low-income patients, 5\%), and one patient walked to our clinic.

By 6 months, only 20 participants had shared logbook data, so at that time, follow-up questions were added to the surveys providing additional practice frequency data on 17 of the subjects for the 2-month visit, and all but 7 subjects for the 6month visit.

Three of the 40 enrolled subjects who left the treatment program and the study for reasons other than documented or presumed relapse were excluded from these analyses.

Thirty-four subjects completed the 2-month survey, which contained four questions specific to their recollection of the education session conducted by a family physician and feelings about that session (Likert scale agreement scores $1-6,1=$ strongly disagree to $6=$ strongly agree). Responses were generally positive (Table 2 ).

At each follow-up visit at 2, 4, and 6 months, the authors asked questions to assess patient perceptions of the ease and usefulness of the exercises. Generally positive responses were sustained throughout, especially for ease of practice (Table 3 ).

\section{Intervention behavior uptake}

In terms of practice frequency, the authors noticed that the mean number of sessions per week actually rose over time, especially when those who did not practice at all were removed (thereby averaging just among those who were reporting some practice) (Table 4).
Table 4. Mean Number of Mindfulness

Practice Sessions Per Week at 2, 4, and 6 Months (Survey Data)

\begin{tabular}{lccc}
\hline & $\begin{array}{c}\text { At } \\
2 \text { months }\end{array}$ & $\begin{array}{c}\text { At } \\
\text { months }\end{array}$ & $\begin{array}{c}\text { At } \\
\text { months }\end{array}$ \\
\hline $\begin{array}{c}\text { Mean number of } \\
\text { sessions/week, } \\
\text { all respondents }\end{array}$ & $2.5(N=17)$ & $2.6(N=20)$ & $3.4(N=20)$ \\
$\begin{array}{c}\text { Mean sessions/ } \\
\text { week, removing } \\
\text { nonpracticers }\end{array}$ & $3.0(N=14)$ & $3.4(N=15)$ & $4.0(N=17)$ \\
\hline
\end{tabular}

Survey data also evaluated practice intensity, asking subjects the average length of mindfulness practice sessions in the past 2 months. No clear increase occurred over time, and these practice amounts are much lower than typically taught or recommended in the context of MBSR and related protocols. In combination with the practice frequency data (3-4 times/week), this suggests an average number of minutes per week of practice that is only 15-20 min for many of these subjects (Fig. 2).

In terms of practice persistence, the survey asked patients how many days it had been since they last did mindfulness exercises. At every follow-up, about two thirds of subjects responding reported practicing within the last 5 days $(65 \%-$ $70 \%$ ), suggesting a high level of sustained mindfulness practice behavior uptake for a significant subset of patients (Fig. 3).

\section{Relapse outcome}

Excluding 3 subjects who left treatment for documented reasons other than relapse 10 of the 37 patients met the definition of relapse or treatment failure before 6 months following their intervention date $(27 \%) ; 27$ remained in treatment at 6 months. Based on classification by "high" versus "low" mindfulness practice behavior uptake, there was a significantly reduced rate of relapse in the "high", practice uptake group ( $11 \%$ vs. $42 \%$, relative risk $=0.26$, $p=0.033$ ). Sample size was too small to achieve significance for the multivariate analysis of the covariates.

\section{Poststudy semi-structured interview analysis, themes, and quotations}

Eighteen subjects agreed to a semi-structured poststudy interview; 17 of these were audio-recorded on a smartphone

Table 3. Survey Questions at 2, 4, and 6 Months of Follow-up About Effects of Mindfulness Practice

\begin{tabular}{|c|c|c|c|}
\hline Question & $\begin{array}{c}\text { Mean at } 2 \text { months } \\
(\mathrm{N}=34)\end{array}$ & $\begin{array}{l}\text { Mean at } 4 \text { months } \\
(\mathrm{N}=31)\end{array}$ & $\begin{array}{l}\text { Mean at } 6 \text { months } \\
(\mathrm{N}=24)\end{array}$ \\
\hline $\begin{array}{l}\text { I found it easy to access the audio files to practice } \\
\text { mindfulness exercises at home. }\end{array}$ & 4.6 & 5.0 & 4.8 \\
\hline $\begin{array}{l}\text { I found it relaxing to practice listening to the audio } \\
\text { files at home. }\end{array}$ & 4.7 & 4.6 & 4.6 \\
\hline $\begin{array}{l}\text { I felt better able to cope with cravings to use opiates } \\
\text { because of the mindfulness exercises. }\end{array}$ & 4.5 & 4.3 & 4.2 \\
\hline $\begin{array}{l}\text { I have found the mindfulness exercises helpful to me } \\
\text { in my daily life to cope with stressful situations. }\end{array}$ & 4.5 & 4.5 & 4.5 \\
\hline $\begin{array}{l}\text { I would like more training or resources to improve } \\
\text { my mindfulness practice skills. }\end{array}$ & 4.1 & 3.8 & 3.7 \\
\hline
\end{tabular}




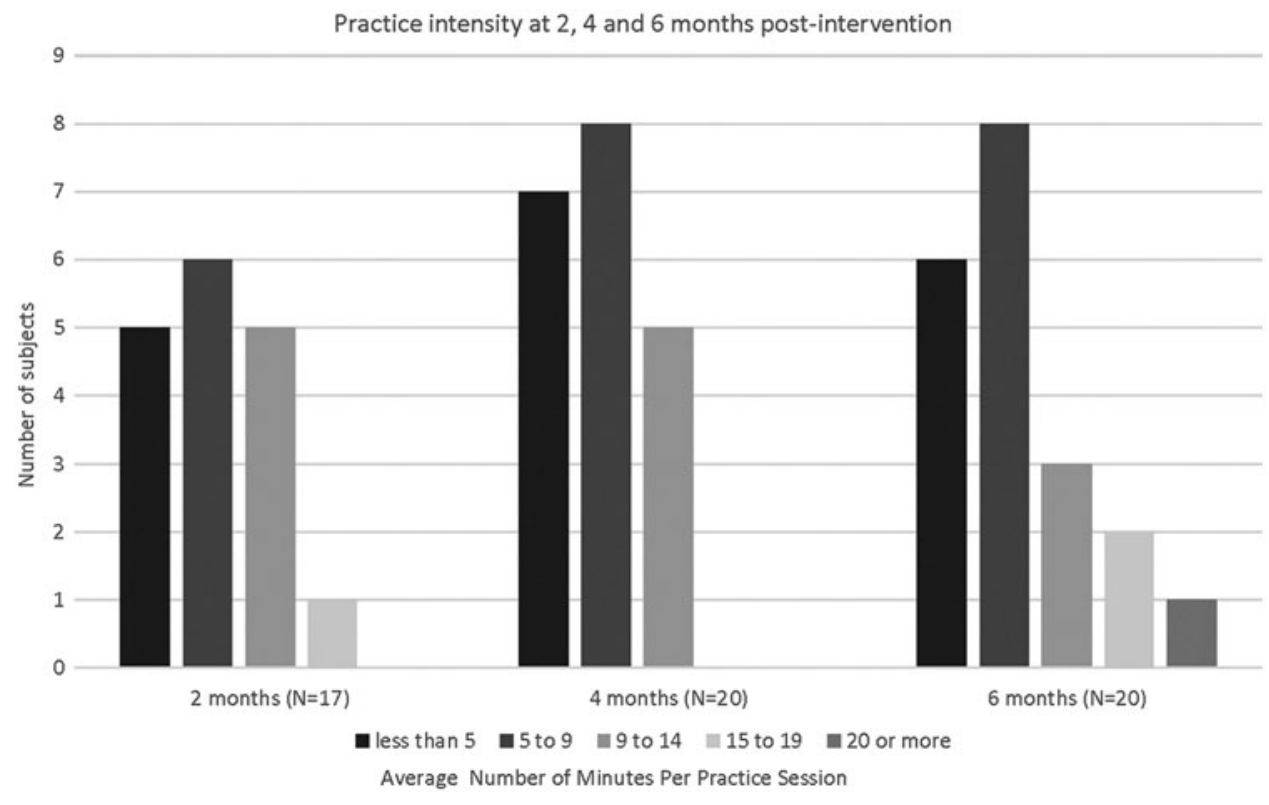

FIG. 2. Minutes of practice per session, on average (survey data).

with written consent and transcribed for coding and qualitative analysis. In response to a general question of what they thought of participating in the study, 15 subjects offered a positive or very positive response (e.g., "it was good," "it helped"), 1 subject expressed only mildly positive ("It was okay"), and 1 subject expressed having struggled with their participation ("The exercises made me frustrated").

The interviews did provide some feedback on which specific exercises were most helpful. Eleven of the 17 subjects $(64 \%)$ reported having at least tried all 6 of the exercises provided and 5 said that they did not try them all (for one, the response was unclear). Three respondents mentioned eventually meditating on their own or using other recordings such as music, but the majority reported still using the MP3 player at 6 months if they were still medi- tating. Table 5 shows how frequently each exercise was reported as most or least helpful.

Subjects were also asked about the most difficult thing about practicing the exercises or what they did not like, and the greatest barriers they had to practicing the exercises. By far, the challenges created by having small children in the home were the most mentioned, followed by difficulty in finding a quiet space and lack of time in general. Table 6 describes the responses offered to these questions.

The most common themes that came up about the positive effects of the mindfulness practice and how many subjects mentioned them are described in Table 7 with a few representative quotations.

Some of the stories shared by patients are characterized by the participants having noticed a substantial change in

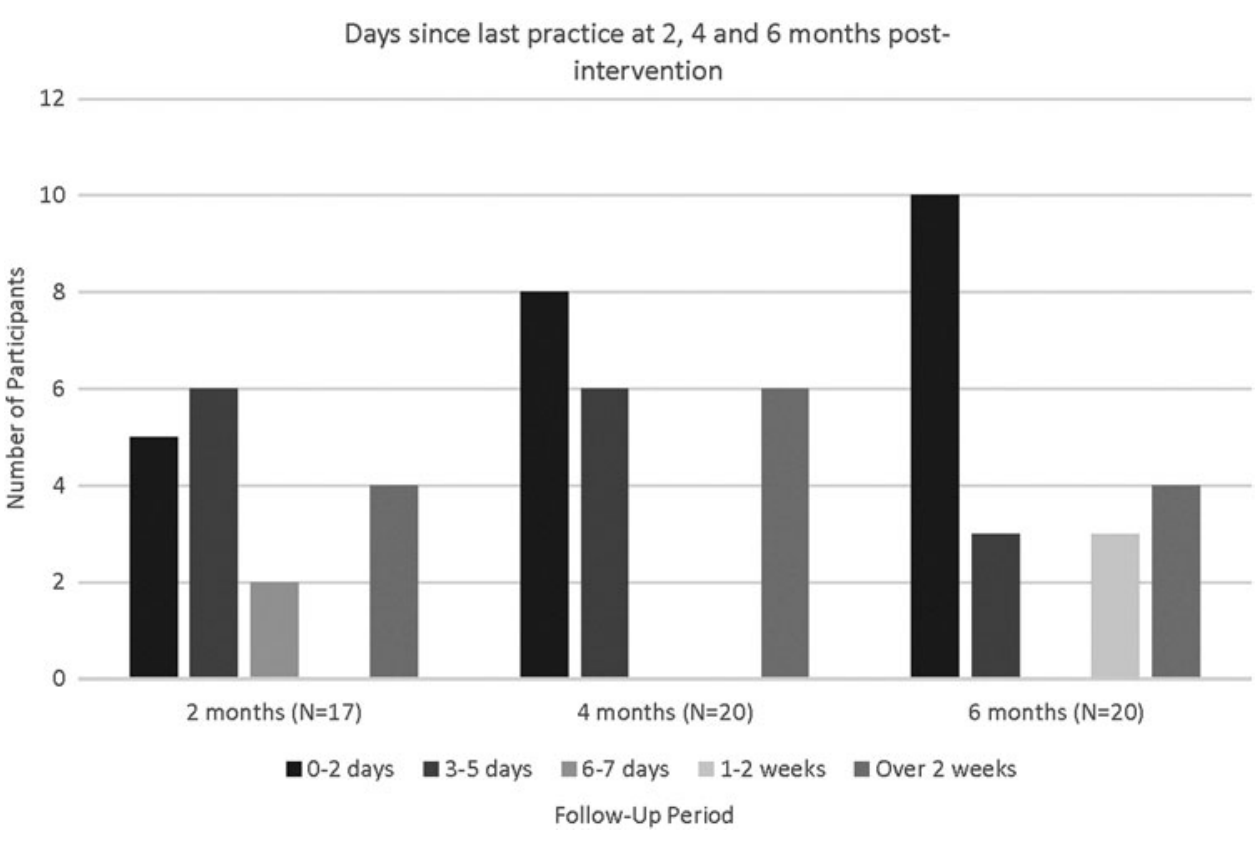

FIG. 3. Practice persistence (number of subjects reporting range of days since last practice, survey data). 
Table 5. Interview Subjects' Response to Questions About Which Exercise Was Most/Least Helpful

\begin{tabular}{lcc}
\hline Exercise & $\begin{array}{c}\text { Subjects } \\
\text { noting most } \\
\text { helpful }\end{array}$ & $\begin{array}{c}\text { Subjects } \\
\text { noting least } \\
\text { helpful }\end{array}$ \\
\hline $\begin{array}{l}\text { 1: Breathing slow and low } \\
\text { 2: Thoughts as leaves }\end{array}$ & 5 & 2 \\
$\quad 2$ & 1 \\
3: Breath-focused & 2 & 0 \\
mindfulness & 5 & 1 \\
$\begin{array}{l}\text { 4: Body scan } \\
\text { 5: Surfing the urge }\end{array}$ & 1 & 1 \\
$\begin{array}{l}\text { All Walking meditation } \\
\quad \text { of them them }\end{array}$ & 2 & 2 \\
Not indicated & 0 & $\begin{array}{c}\text { None } \\
\text { All helpful: } 2\end{array}$ \\
\hline
\end{tabular}

the way that they managed difficult situations, which they related to having learned skills of mindfulness meditation. Some representative longer quotations from interviews are included below.

Subject 8: I got my head caved in. This guy hit me with a pipe. It was all over money that he owes me for drugs, and I wanted to retaliate, and retaliate, and I thought about it, and I thought it through. I took deep breaths, and that's where, that's when I used it ... Just yesterday, this, this guy at the shelter, right there, he's like, "oh!" he goes, "you start snoring tonight," he goes, "you're gonna end up dead," and I thought, I wanted to get up and I wanted to hit him. And I was like [demonstrates taking a deep breath slowly in and $o u t]$ and it worked. I went to the office, and I said, "Listen. I'm not threatening, I'm not making no threats, but I'm gonna tell you what he said, and this is what I said to him. I told him, 'I'm not the person he wants to push, because I can promise you, we'll have an issue." And he [the man in the office] goes, "You handled that perfect." He goes, "You didn't make any threats. You didn't threaten to hurt him." And I said, "No, I wanted to! But I thought it through and took a deep breath."

Subject 10: When the baby aspirated her formula, and we had to take her to the hospital in the middle of the night. She coughed while she was eating and aspirated her formula and she couldn't breathe, and we had to rush her to the hospital. It kept me calm and I was able to be there for her in the moment.

Subject 14: When I was in a car accident, I used slow breathing. I was in shock. I was scared so I started breathing. Yeah. I thought I was gonna die; I wasn't sure. So, I just used my breathing tools to try to relax. My leg was stuck up in the air, the head was out of the socket, so. It was painful, too, so. I was breathing to make the pain go away.

Subject 17: Um, well, I till recently wasn't able to talk about the passing of my daughter [from SIDS] without totally losing it. Um, and I still do cry sometimes, but it's not ... unending. Never ending. I'm able to put those feelings away, understand that they're still there, they're still very real, but that's it's okay for me to continue experiencing other feelings and emotions. I'm not stuck in the moment anymore, and it's helping me deal with that.

\section{Discussion}

This research is the first to explore the use of an ultrabrief mindfulness-based training in the outpatient primary care OUD treatment practice setting. The intervention was developed as one that could be realistically conducted by a primary care physician within the usual constraints of a primary care office setting. Efficiently addressing

Table 6. Interview Subjects' Response to Questions about Challenges/Barriers to Mindfulness Practice

\begin{tabular}{|c|c|c|}
\hline Challenge/barrier & Number & Quotations \\
\hline Kids & $10 / 17$ & $\begin{array}{l}\text { "Finding time away from my } 2 \text { year old" (\#1); "Right here is one of the barriers } \\
\text { [laughing, indicating infant]" (\#11); "between just doing stuff around the house, and } \\
\text { work, and the little munchkins running around"" (\#12); "If I didn't have a } 1 \text { year old } \\
\text { it'd probably be easier. He takes up most of my time." (\#15) }\end{array}$ \\
\hline Work & $3 / 17$ & $\begin{array}{l}\text { "I just never had enough time in which I wasn't working or taking care of children or } \\
\text { running errands." (\#8) }\end{array}$ \\
\hline Lack of quiet space & $5 / 17$ & $\begin{array}{l}\text { "When I was doing it I was working } 12 \text { hour days, and yeah I was I living with my } \\
\text { parents ... people, brother, hard to find a quiet spot sometimes" (\#5); "Finding a } \\
\text { quiet spot to do it, and be by myself" (\#8); "trying to find quiet, is hard." (\#10) }\end{array}$ \\
\hline Doctors appointments & $2 / 17$ & "Full schedule, my homework, baby appointments, my doctor's appointments" (\#10) \\
\hline General lack of time & $4 / 17$ & $\begin{array}{l}\text { "When you have children and you have to work, there's never enough time to do } \\
\text { anything else." (\#9) }\end{array}$ \\
\hline Remembering & $2 / 17$ & $\begin{array}{l}\text { "Remembering to do it every day" (\#4); "Remembering to bring it with me places, } \\
\text { because I would have time sometimes, but I wouldn't always have it with me." (\#13) }\end{array}$ \\
\hline Technical problems & $3 / 17$ & $\begin{array}{l}\text { "Keeping the MP3 player charged"” (\#2); "The MP3 player was difficult to operate, } \\
\text { hard to push the buttons." (\#4); "It was just time consuming. There should be a faster } \\
\text { way. It was just outdated technology." (\#6) }\end{array}$ \\
\hline Partner & $1 / 17$ & "Well, my girlfriend, always complaining about my taking the time" (\#14) \\
\hline Had no barriers & $3 / 17$ & $\begin{array}{l}\text { "No barriers because I had plenty of time" (\#2); "I don't know if there were any } \\
\text { barriers. I think when people first get into recovery, that has to be the focus/priority." } \\
\text { (\#4); "Not really, I don't think so. Because really, you can take five minutes of time, } \\
\text { I mean, everybody has five minutes. Somewhere. You just have to look for it." (\#17) }\end{array}$ \\
\hline
\end{tabular}


Table 7. Common General Positive Themes from Poststudy Interviews

\begin{tabular}{|c|c|c|}
\hline Theme & Number & Quotations \\
\hline $\begin{array}{l}\text { It was calming/relaxing to do the } \\
\text { exercises }\end{array}$ & $15 / 17$ & $\begin{array}{l}\text { "Just the gratification of having that calmness after, almost like getting } \\
\text { high" (\#7); "I had a positive experience with it, calming me down and } \\
\text { helping me get through tough issues." (\#10); "Helped me think a little } \\
\text { more and calm down" (\#11); "Breathing sessions brought me sense of } \\
\text { peace" (\#14); "Helped me to relax and not think about anything for a } \\
\text { moment" (\#16) }\end{array}$ \\
\hline Helped tolerate or cope with stress & $14 / 17$ & $\begin{array}{l}\text { "When I get stressed out or whatever just start to breathe and helps me } \\
\text { think about what I'm going to do or not do" (\#2); "I think I do now, } \\
\text { when I'm stressed about things at work or home life, I try to remember to } \\
\text { stay in the moment" (\#4); "Yeah-like the stress thing. Help with the } \\
\text { new baby." (\#13); "Helps to deal with your kids, helps to deal with the } \\
\text { stress of life."” (\#15) }\end{array}$ \\
\hline $\begin{array}{l}\text { Helped with controlling anger or } \\
\text { impulses }\end{array}$ & $9 / 17$ & $\begin{array}{l}\text { "It puts me in a place where I can address people without screaming at } \\
\text { them ... Last week helped me not go across the street and punch this girl } \\
\text { out." (\#1); "Quiets the loud noise in my head and allows me to have } \\
\text { discipline and not be impulsive and stay out of jail" (\#7); "kept me from } \\
\text { saying something I'd regret" (\#11) }\end{array}$ \\
\hline Helped focus/set or reach goals & $7 / 17$ & $\begin{array}{l}\text { "I think I used meditation really well to focus on what I'm doing in the } \\
\text { moment, not focus on the past or get anxiety about tomorrow" (\#4); "It } \\
\text { helped me to refocus, tune everybody out" (\#5); "I was able to focus a } \\
\text { bit better, on my goals, like I opened up a savings account. It's only got } 5 \\
\text { bucks in it, but. It's a start." (\#9) "it actually made me focus more on my } \\
\text { breathing compared to what was around me"" (\#11) "The mind-body } \\
\text { scan was the most helpful. It was the one that helped me focus on } \\
\text { something outside of my thoughts for a little while. It just relaxed me. It } \\
\text { gave me something like a part of my body on which to concentrate" } \\
\text { (\#17) }\end{array}$ \\
\hline $\begin{array}{l}\text { A new strategy/had not tried before/ } \\
\text { had not expected to help }\end{array}$ & $6 / 17$ & $\begin{array}{l}\text { "Sometimes I just count down from } 10 \text { taking deep breaths. I never tried } \\
\text { anything like that before the mindfulness study." (\#1); "still to this day, I } \\
\text { take deep breaths now and I calm myself down, and I never used to be } \\
\text { able to." (\#8); "I thought it wouldn't help but it did and it calmed me and } \\
\text { I got my mother doing it." (\#9); "some arguments with my boyfriend or } \\
\text { something, like I just close my eyes, and like try to breathe, you know } \\
\text { what I mean, like. I do that. I used to not do that" (\#11) }\end{array}$ \\
\hline Helped recovery/cravings, not using & $5 / 17$ & $\begin{array}{l}\text { "to keep the cravings down, stay away from any, you know, bad choices." } \\
(\# 5) \text {; "I know that I have had a few cravings. I don't have "em all the } \\
\text { time, but it's definitely helped." (\#9) "Helped me stay clean." (\#14) }\end{array}$ \\
\hline Helped blood pressure & $3 / 17$ & $\begin{array}{l}\text { "Probably my blood pressure." (\#3); "Because now if my blood pressure } \\
\text { is going up or if I'm freaking out, it helps to just take a deep breath in and } \\
\text { out slowly." (\#6); "My blood pressure, I mean, I know that for sure, it } \\
\text { definitely helps with you, sometimes it's sky high, and you do that, you } \\
\text { feel it" (\#9) }\end{array}$ \\
\hline
\end{tabular}

substance abuse, tobacco cessation, and mood disorders is a routine part of primary care practice. ${ }^{26}$ The authors used a model of an ultra-brief intervention toward therapeutic lifestyle change-through which a physician might analogously spend $5 \mathrm{~min}$ motivating a patient to quit smoking or teaching a patient simple stretches and healthy posture for back pain-to teach patients self-management skills that promote metacognitive awareness and greater cognitive control over cravings and negative emotions.

Previous studies have shown that mindfulness training is feasible in the primary care setting, specifically the use of mindfulness-based cognitive therapy for mixed diagnosis patients, showing low attrition and comparable attendance and engagement with home practice to other studies. ${ }^{18,19}$ A metaanalysis of six randomized controlled trials of mindfulnessbased interventions (intensive 8-week programs) in primary care patients found moderate efficacy for improving general health $(g=0.48)$, mental health $(g=0.56)$, and quality of life $(g=0.29) .{ }^{27}$ Other studies have demonstrated that brief mindfulness meditation training has measurable impacts on cardiovascular physiology, ${ }^{20}$ pain tolerance,${ }^{28,29}$ scores on scales of attention, depression, and anxiety, and work-related stress. ${ }^{22,30}$ Among smokers, brief mindfulness training has been shown to reduce depressive symptoms, nicotine dependence, and craving in response to smoking cues. ${ }^{8,21,31}$ However, brief mindfulness interventions have not previously been studied in the primary care setting for the treatment of OUD.

This pilot study supports the feasibility and acceptability of a very briefly taught mindfulness intervention supported by material for home practice in this high-risk population of young patients with OUD as well as abuse of multiple other substances and comorbid mental health diagnoses, who are 
starting outpatient treatment for OUD with buprenorphine. By collecting data on practice uptake using three different methods, it was possible to demonstrate that the very brief intervention, accompanied by the MP3 player, did induce patients to practice mindfulness on their own to a considerable and sustained degree. Although practice quantities in minutes per week were well below those which other mindfulness studies typically seek, approximately two thirds of subjects who completed surveys at every follow-up reported having practiced mindfulness meditation within the past 5 days and the average frequency of practice sessions per week increased over the time of the study.

Despite the small number of subjects, a statistically significant difference was found in the relapse rate between those who had higher uptakes of home mindfulness practice and those whose uptake was lower. This finding could be confounded by many psychological or psychosocial factors that could both diminish home practice uptake and decrease likelihood of success in treatment (e.g., greater barriers to finding time and quiet space for practice suggest a home environment that may not be associated with enough support in recovery). However, the qualitative analysis of the poststudy interviews combined with the behavior uptake data provides evidence that despite the brief nature of the educational intervention, there was significant sustained use of meditation practice in this patient population through 6 months of addiction treatment in a higher than expected percentage of patients. The practice was new to many of the subjects, and mindfulness practice appeared to result in subjective benefits for stress, impulse control, and anger management. That the practice frequency increased over time based on both interview and survey data for many subjects was an unexpected finding, suggesting that a low rate of practice initially can still demonstrate enough benefit to promote increased practice over time, even without regular clinical reinforcement. The narratives quoted above are especially powerful regarding the impact such a brief intervention, supported by home practice materials, may have.

\section{Limitations}

The authors acknowledge the typical limitations of a pilot/feasibility study of having a small group of patients and therefore being underpowered to find differences in other outcomes measures. In addition, as a feasibility pilot study, there was no control group, and there are likely important differences between the subjects that will develop a home mindfulness practice and those that will not.

All the self-reported data (surveys, logbooks, and interviews) are subjected to social desirability and recall bias. Attempts were made where possible to assure subjects of anonymity to decrease social desirability bias. However, poststudy interviews were conducted by primary study investigators, and subjects may have had a desire to provide positive responses to them. A future larger study would benefit from having a neutral party unknown to the subjects to conduct interviews or focus groups. Recall bias may also have been a factor in the accuracy of the survey data collected at follow-up visits, particularly with regard to mindfulness home practice patterns.

\section{Conclusions}

What is most unexpected about these results and unpredicted by previous research on mindfulness is the finding that very little training and support was associated with substantial benefit to participants. These results challenge the usual bias in mindfulness circles that a prolonged training period is needed for successful interventions. A very brief mindfulness intervention in a primary care setting supported by home audio materials showed promise in preventing relapse for patients starting treatment for OUD with buprenorphine. Further research with a randomized design is warranted to determine the optimal and most cost and time effective method for mindfulness training and will hopefully be underway shortly.

\section{Acknowledgments}

The authors thank Andrew Pritchard, Nina Vekima, and Dr. Barbara Sorondo from the Northern Light Eastern Maine Medical Center Clinical Research team for their assistance.

\section{Authors' Contributions}

Dr. Eric Brown; Patrick McFarlane, PMH-NP, LCSW, FNP; and Matt Nutt, LCSW, were essential contributors to the study's design and execution. Tradewinds/Citgo of Bangor, Maine, contributed toward the gas cards provided as compensation to subjects.

\section{Author Disclosure Statement}

No competing financial interests exist.

\section{Funding Information}

This study was funded in part by a Joint Grant Awards Program grant from the American Academy of Family Physicians.

\section{References}

1. CDCVitalSigns ${ }^{\mathrm{TM}}$. Prescription Painkiller Overdoses: A Growing Epidemic, Especially Among Women, 2013.

2. Fraga B. CDC statistics show opiate addiction a growing threat across country. Herald News, 2014.

3. Bowen S, Witkiewitz K, Clifasefi SL, et al. Relative efficacy of mindfulness-based relapse prevention, standard relapse prevention, and treatment as usual for substance use disorders: A randomized clinical trial. JAMA Psychiatry 2014;71:547-556.

4. Witkiewitz K, Bowen S, Douglas H, et al. Mindfulnessbased relapse prevention for substance craving. Addict Behav 2013;38:1563-1571.

5. Bowen S, Chawla N, Collins S, Witkiewitz K. Mindfulnessbased relapse prevention for substance use disorders: A pilot efficacy trial. Subst Abus 2009;30:295-305.

6. Witkiewitz K, Bowen S. Re-training the addicted brain: A review of hypothesized neurobiological mechanisms of mindfulness-based relapse prevention. Psychol Addict Behav 2013:27:351-365.

7. Witkiewitz K, Bowen S, Harrop EN, et al. Mindfulnessbased treatment to prevent addictive behavior relapse: Theoretical models and hypothesized mechanisms of change. Subst Use Misuse 2014;49:513-524. 
8. Bowen S, Marlatt A. Surfing the urge: Brief mindfulnessbased intervention for college student smokers. Psychol Addict Behav 2009;23:666-671.

9. Zgierska A, Rabago D, Chawla N, et al. Mindfulness meditation for substance use disorders: A systematic review. Subst Abus 2009;30:266-294.

10. Bowen S, Chawla N, Marlatt G. Mindfulness-Based Relapse Prevention for Addictive Behaviors: A Clinician's Guide. New York City: The Guilford Press, 2011.

11. Williams R, Kraft J. The Mindfulness Workbook for Addiction. Oakland, CA: New Harbinger Publications, 2012.

12. Grow JC, Collins SE, Harrop EN, Marlatt GA. Enactment of home practice following mindfulness-based relapse prevention and its association with substance-use outcomes. Addict Behav 2014;40C:16-20.

13. Kabat-Zinn J. Full Catastrophe Living: Using the Wisdom of Your Body and Mind to Face Stress, Pain, and Illness. New York City: Delta, 1990.

14. Carlson LE. Mindfulness-based interventions for physical conditions: A narrative review evaluating levels of evidence. ISNR Psychiatry 2012;2012:651583.

15. Grossman $P$, Niemann L, Schmidt $S$, Walach $H$. Mindfulness-based stress reduction and health benefits: A meta-analysis. J Psychosom Res 2004;57:35-43.

16. Merkes M. Mindfulness-based stress reduction for people with chronic diseases. Aust J Prim Health 2010;16:200 210.

17. Black D. Mindfulness-based interventions: An antidote to suffering in the context of substance use, misuse, and addiction. Subst Use Misuse 2014;49:487-491.

18. Finucane A, Mercer SW. An exploratory mixed methods study of the acceptability and effectiveness of MindfulnessBased Cognitive Therapy for patients with active depression and anxiety in primary care. BMC Psychiatry 2006; $6: 14$.

19. Radford CR, Crane RS, Dipcot MA, et al. The feasibility and effectiveness of mindfulness-based cognitive therapy for mixed diagnosis patients in primary care: A pilot study. Ment Health Fam Med 2012;9:191-200.

20. Ditto B, Eclache M, Goldman N, Med AB. Short-term autonomic and cardiovascular effects of mindfulness body scan meditation. Ann Behav Med 2006;32:227-234.

21. Westbrook C, Creswell JD, Tabibnia G, et al. Mindful attention reduces neural and self-reported cue-induced craving in smokers. Soc Cogn Affect Neurosci 2013;8: 73-84.

22. Tang Y, Ma Y, Wang J, et al. Short-term meditation training improves attention and self-regulation. PNAS 2007;104: 17152-17156.

23. Garland EL, Hanley AW, Thomas EA, et al. Low dispositional mindfulness predicts self-medication of negative emotion with prescription opioids. J Addict Med 2015;9:61-67.

24. Behler J, Daniels A, Scott J, Mehl-Madrona L. Depression/ Bipolar Peer Support Groups: Perceptions of Group Members about Effectiveness and Differences from Other Mental Health Services. Qual Rep 2017;22:213-236.

25. Fram SM. The constant comparative analysis method outside of grounded theory. Qual Rep 2013;18:1-25.

26. Koven S. Should Mental Health Be a Primary Care Doctor's Job? New Yorker, 2013. Online document at: http:// www.newyorker.com/tech/elements/should-mental-healthbe-a-primary-care-doctors-job accessed July 2, 2019.

27. Demarzo M, Montero-Marin J, Cuijpers P, et al. The efficacy of mindfulness-based interventions in primary care: A meta-analytic review. Ann Fam Med 2015;13:573-582.

28. Liu X, Wang S, Chang S, et al. Effect of brief mindfulness intervention on tolerance and distress of pain induced by cold-pressor task. Stress Health 2013;29:199-204.

29. Zeidan F, Gordon NS, Merchant J, Goolkasian P. The effects of brief mindfulness meditation training on experimentally induced pain. J Pain 2010;11:199-209.

30. Gregoire S, Lachance L. Evaluation of a brief mindfulnessbased intervention to reduce psychological distress in the workplace. Mindfulness (N.Y.). 2014. DOI: 10.1007/s12671014-0328-9.

31. Rogojanski J, Vetesse LC, Antony MM. Coping with cigarette cravings: Comparison of suppression versus mindfulnessbased strategies. Mindfulness (N.Y.) 2010;2:14-26.

Address correspondence to:

Jessica Bloom-Foster, MD

Family Medicine Residency

Northern Light_Eastern Maine Medical Center

895 Union St.

Bangor, ME 04401

E-mail: jbloomfoster@ northernlight.org 